\title{
Alveolar Rhabdomyosarcoma of the Lip in an Adult with Clear Cell Features
}

\author{
Jae Yeon Seok · Juhyeon Jeong · Young Woo Cheon ${ }^{1} \cdot$ Hyun Yee Cho · Seung Yeon Ha · Dong Hae Chung \\ Departments of Pathology and PPlastic Surgery, Gachon University Gil Medical Center, Incheon, Korea
}

Rhabdomyosarcoma, which occurs in the head and neck, genitourinary tract and deep soft tissue of the extremities and typically presents in childhood or adolescence, is a malignant mesenchymal tumor showing differentiation of skeletal muscle. ${ }^{1,2}$ Less than $3 \%$ of rhabdomyosarcoma cases present in adults. Although rhabdomyosarcoma frequently occurs in the head and neck region, involvement of the lips is very rare; only 8 cases have been reported in the English literature. ${ }^{3-10}$ Conventionally, rhabdomyosarcoma is categorized into embryonal, alveolar and pleomorphic subtypes. ${ }^{11}$ We report a case of alveolar rhabdomyosarcoma with clear cell features presenting as a perioral subcutaneous nodule on the upper lip of a 58-year-old woman. A review of the literature and possible differential diagnoses are described.

\section{CASE REPORT}

A 58-year-old woman presented with a subcutaneous hard mass on her upper lip (Fig. 1A). A punch biopsy was performed at a local clinic and revealed small round cells infiltrating the dermis. The possibility of a small round cell tumor such as Merkel cell carcinoma or lymphoma was suggested. A wide excision was performed, and a skin-colored $0.7-\mathrm{cm}$ nodule was noted. The cut surface of the mass was white gray and firm. Microscopic findings showed an ill-defined subcutaneous tumor that involved the entire dermis and subcutaneous adipose tissue sparing the epidermis (Fig. 1B, C). Small tumor cells infiltrated

\section{Corresponding Author}

Dong Hae Chung, M.D.

Department of Pathology, Gachon University Gil Medical Center, 21 Namdong-daero 774beon-gil, Namdong-gu, Incheon 405-760, Korea

Tel: +82-32-460-3073, Fax: +82-32-460-2394, E-mail: dhchung@gilhospital.com

Received: February 25, 2014 Revised: May 30, 2014

Accepted: June 3, 2014 dissecting dermal collagen bundles and showed densely packed groups of cells. The cytoplasm was scanty with indistinct borders, and marked clear cell change was noted in most of the tumor cells (Fig. 1D). Some tumor cells had amphophilic cytoplasm. The nuclei were round to oval with focal indentation and finely granular chromatin. Frequent mitotic figures were noted up to 7 per 10 high power fields.

Periodic acid-Schiff stain demonstrated a few intracytoplasmic glycogen particles (Fig. 2A). Immunohistochemical examination of the tumor cells showed strong positivity for desmin, myogenin, and vimentin (Fig. 2B, C). The tumor cells were negative for cytokeratin, smooth muscle actin, human melanoma black 45, S-100 protein, and neuron-specific enolase. Under electron microscopy, the tumor cells showed thin and thick filaments with focal electron density in the cytoplasm, and many vacuoles which corresponds to clear cytoplasm visualized under light microscopy (Fig. 2D). These findings confirmed the diagnosis of rhabdomyosarcoma, alveolar type.

After the diagnosis, head and neck computed tomography and positron emission tomography were performed and revealed no evidence of a primary tumor elsewhere or evidence of a mass in deeper soft tissue. The patient underwent radiation therapy and was free of recurrence or metastasis for four months after surgery.

\section{DISCUSSION}

Rhabdomyosarcoma arising in the lip is very rare. Only eight cases have been reported in the English literature (Table 1), ${ }^{3-10}$ and the patients ranged in age from 1 to 58 years. Three of nine patients including the current case were adults, and four of nine patients were male. Six patients had a mass in the upper lip. Three 

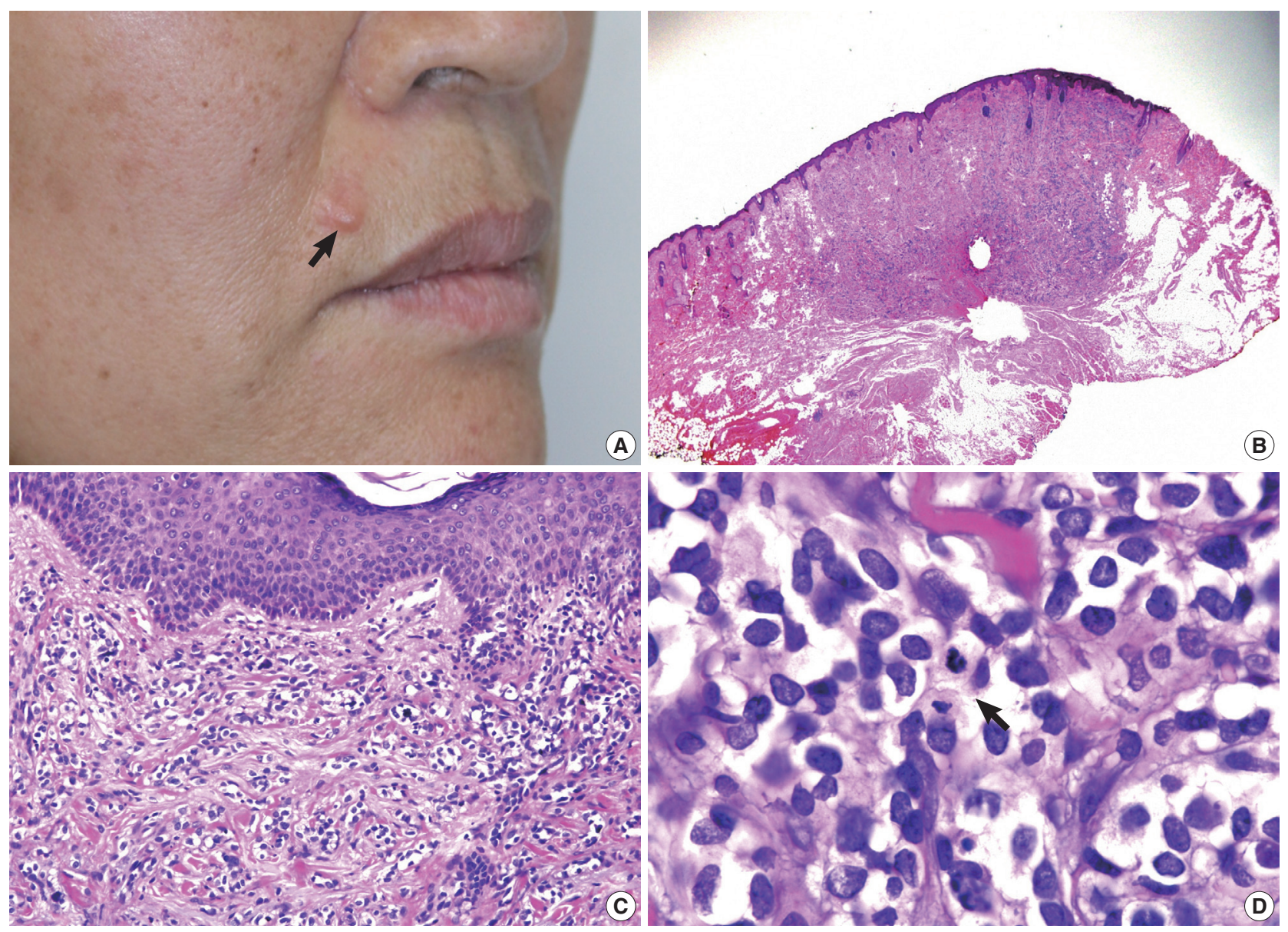

Fig. 1. (A) A skin-colored nodule is noted in the upper lip (arrow). (B) An ill-defined mass involves the dermis and subcutaneous fat tissue. (C) The tumor cells extend to the papillary dermis but do not invade the epidermis. (D) The tumor is composed of densely packed groups of small round cells intersecting collagen bundles with marked clear cell change and frequent mitotic figures (arrow).

of nine patients presented with a congenital mass. The duration of symptoms ranged up to seven months, and the tumor size ranged from $0.7 \mathrm{~cm}$ to $10 \mathrm{~cm}$. Five patients were diagnosed as alveolar subtype, three patients as embryonal subtype, and one patient as pleomorphic subtype. The follow-up period ranged from 3 to 71 months. None of the nine patients experienced local recurrence, but two had metastatic lesions. One patient had metastatic lesions at the cervical lymph node and salivary gland. The other patient had metastatic lesions at the lung and bone, who died of the disease within three months.

Rhabdomyosarcoma of the lip as a primary lesion is rare. The previously reported cases showed various clinical features such as ulcerated hemorrhagic soft mass, smooth mobile nodule, firm lobulated erythematous mass, lobulated small raised lesion, painful swelling and tender firm indurated mass. The clinical differential diagnoses include hemangioma, odontogenic tumor, dermoid, solitary fibromatosis, gingival granular cell tumor, neurofibroma and rhabdomyosarcoma. Microscopically, when the tumor shows skeletal muscle differentiation such as a rhabdoid feature, strap cells or cytoplasmic striation, it is easy to reach a diagnosis of rhabdomyosarcoma. However, in the case of a small biopsy or small tumor, the diagnosis may be more obscure. Several tumors including lymphoma, Ewing sarcoma and rhabdomyosarcoma can show the histologic features of a small round cell tumor. Suspicion of this diagnosis and an extensive search for the signs of differentiation on light microscopy are needed in such cases. An immunohistochemical study including desmin and myogenin is helpful if tumor cells do not show characteristic differentiation on light microscopy. Electron microscopy and genetic study are useful when the immunohistochemical staining is not diagnostic. Ultrastructural rhabdomyosarcoma tumor cells show cytoplasmic thick and thin filaments resembling rudimentary sarcomeric structure, cross striation, and glycogen particles. 

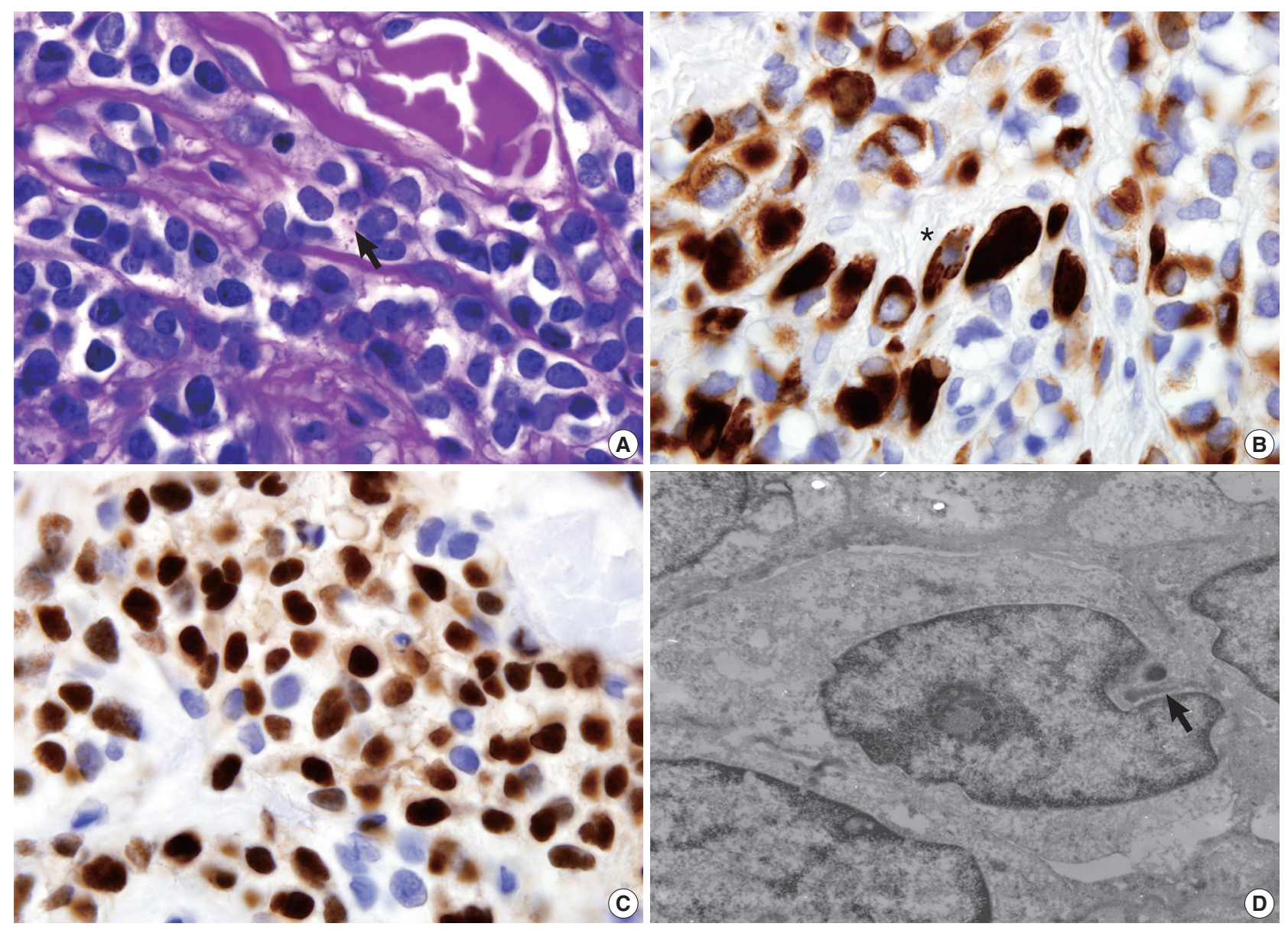

Fig. 2. (A) Periodic acid-Schiff stain shows a few glycogen particles in the cytoplasm (arrow). (B) The cytoplasm is intensively immunoreactive for desmin, and a tumor cell shows striation-like features in the cytoplasm (asterisk). (C) The nuclei are positive for myogenin immunohistochemical stain. (D) Ultrastructurally, the tumor cell shows intracytoplasmic filaments (arrow) $(\times 60,000)$.

Table 1. Clinicopathologic features of rhabdomyosarcoma of the lip

\begin{tabular}{|c|c|c|c|c|c|c|c|c|c|}
\hline Author & Year & Age & Sex & Site & Duration & Size $(\mathrm{cm})$ & Type & Treatment & Recurrence/Metastasis/Follow-up (mo) \\
\hline Smith $^{3}$ & 1962 & $49 \mathrm{yr}$ & M & L & $8 w k$ & NA & E & S & $-/-/ N A$ \\
\hline Piattelli ${ }^{4}$ & 1991 & Adult & NA & $U$ & NA & NA & $P$ & NA & NA/NA/NA \\
\hline D'Amico et al. ${ }^{5}$ & 1996 & $8 \mathrm{mo}$ & M & $U$ & $7 \mathrm{mo}$ & 0.8 & A & $S, C$ & $-/+$ (cervical LN, salivary gland)/alive (NA) \\
\hline Brecher et al. ${ }^{6}$ & 2003 & 2 wk & M & $U$ & Congenital & 4.2 & A & $S, C$ & -l-/alive (6) \\
\hline Seth and Kempert ${ }^{7}$ & 2004 & $3 \mathrm{yr}$ & $\mathrm{F}$ & $L$ & Congenital & 1.5 & E & $\mathrm{S}, \mathrm{C}$ & -/-/alive (60) \\
\hline Marburger et al. ${ }^{8}$ & 2012 & $3 \mathrm{yr}$ & M & NA & NA & NA & A & C & -/-/alive (71) \\
\hline Dhull $^{9}$ & 2012 & $5 \mathrm{yr}$ & $\mathrm{F}$ & U & $3 \mathrm{mo}$ & 10 & A & $\mathrm{R}, \mathrm{C}$ & -/-/alive (6) \\
\hline Singh et al..$^{10}$ & 2013 & 11 day & NA & $U$ & Congenital & 5 & E & C & $-/+($ bone, lung)/dead of disease (3) \\
\hline Present case & 2014 & $58 \mathrm{yr}$ & F & $U$ & Few mo & 0.7 & A & S, C & -/-/alive (3) \\
\hline
\end{tabular}

L, lower lip; M, male; NA, not available; E, embryonal rhabdomyosarcoma; S, surgical treatment; U, upper lip; P, pleomorphic rhabdomyosarcoma; A, alveolar rhabdomyosarcoma; C, chemotherapy; LN, lymph node; F, female; R, radiotherapy.

Rhabdomyosarcoma with clear cell features has been rarely described in the English literature. ${ }^{12,13}$ The clear or vacuolated cytoplasm visible on light microscopy is due to lipid droplets or glycogen particles on electron microscopy. Lipid-rich rhabdomyosarcoma resembles liposarcoma but the tumor cells are immunoreactive to muscle-specific markers such as desmin and myogenin. Variable amounts of glycogen can be observed in rhabdomyosarcoma and can be demonstrated with periodic acid-Schiff stain. The clear cell change itself obscures the definitive diagnosis of rhabdomyosarcoma especially when the clear 
cell features are dominant within the tumor. Tumors presenting as a dermal or subcutaneous nodule, which can show clear cytoplasm, are diverse and include balloon cell nevus, balloon cell melanoma, clear-cell sarcoma, Paget's disease, clear-cell basal cell carcinoma, clear-cell syringoid tumors, clear-cell hidradenoma/hidradenocarcinoma, trichilemmoma/trichilemmocarcinoma, sebaceous neoplasm, lipoma/liposarcoma, cutaneous metastasis from renal cell carcinoma and clear-cell dermatofibroma. ${ }^{14}$

Recently, a great advance in the ability to distinguish each of the subtypes of rhabdomyosarcoma has been demonstrated. ${ }^{11}$ In alveolar rhabdomyosarcoma, reciprocal translocation of $\mathrm{t}(2 ; 13)$ (q35;q14) and $\mathrm{t}(1 ; 13)(\mathrm{p} 36 ; \mathrm{q} 14)$ and their associated fusions were identified. In embryonal thabdomyosarcoma, chromosomal losses (chromosome 9 and 10) and gains (chromosome 8, 2, 7, 11, 12,13 , and 20) occur, as do allelic losses and mutations. Chimeric proteins from the fusion of $\mathrm{PAX} 3$ or $\mathrm{PAX} 7$ with $\mathrm{FOXO} 1$ are expressed in most alveolar rhabdomyosarcoma cases, resulting in the worse prognosis with this subtype.

Due to the rarity of this tumor, the diagnosis of adult rhabdomyosarcoma with clear cell features in the lip may be challenging in daily practice of surgical pathology. If the diagnosis of rhabdomyosarcoma is made in a lip biopsy, clinical investigation should be performed to eliminate the possibility of metastasis from other primary sites. Complete surgical excision and close follow-up are needed because of the possibility of metastasis.

\section{Conflicts of Interest}

No potential conflict of interest relevant to this article was reported.

\section{REFERENCES}

1. Weiss SW, Goldblum JR, Enzinger FM. Enzinger and Weiss's soft tissue tumors. 5th ed. Philadelphia: Mosby Elsevier, 2008.
2. Jung WH, Kim YJ, Jung SH, Yim H, Yoo CJ. Rhabdomyosarcoma in children: histologic subtypes and prognosis. Korean J Pathol 1992; 26: 573-81.

3. Smith JF. Rhabdomyosarcoma of the lower lip. Oral Surg Oral Med Oral Pathol 1962; 15: 454-7.

4. Piattelli A. Pleomorphic rhabdomyosarcoma of the upper lip in an adult patient: report of a case and review of the literature. Acta Stomatol Belg 1991; 88: 57-64.

5. D'Amico AV, Goldwein J, Womer R. Alveolar rhabdomyosarcoma of the lip in an infant. Med Pediatr Oncol 1996; 26: 409-13.

6. Brecher AR, Reyes-Mugica M, Kamino H, Chang MW. Congenital primary cutaneous rhabdomyosarcoma in a neonate. Pediatr Dermatol 2003; 20: 335-8.

7. Seth T, Kempert P. Embryonal rhabdomyosarcoma of lower lip. Ind Pediatr 2004; 41: 858-9.

8. Marburger TB, Gardner JM, Prieto VG, Billings SD. Primary cutaneous rhabdomyosarcoma: a clinicopathologic review of 11 cases. J Cutan Pathol 2012; 39: 987-95.

9. Dhull AK. Primary alveolar rhabdomyosarcoma: a horrendous presentation with miraculous remission. BMJ Case Rep 2012; 2012: bcr2012007657.

10. Singh GB, Arora R, Kumar D, Jain M, Puri V. A rare case of congenital rhabdomyosarcoma with review of the literature. Case Rep Otolaryngol 2013; 2013: 518952.

11. Parham DM, Barr FG. Classification of rhabdomyosarcoma and its molecular basis. Adv Anat Pathol 2013; 20: 387-97.

12. Bégin LR, Schürch W, Lacoste J, Hiscott J, Melnychuk DA. Glycogen-rich clear cell rhabdomyosarcoma of the mediastinum: potential diagnostic pitfall. Am J Surg Pathol 1994; 18: 302-8.

13. Ahmed AA, Tsokos M. Sinonasal rhabdomyosarcoma in children and young adults. Int J Surg Pathol 2007; 15: 160-5.

14. Lázaro-Santander R, Andrés-Gozalbo C, Rodríguez-Pereira C, Vera-Román JM. Clear cell atypical fibroxanthoma. Histopathology 1999; 35: 484-5. 